\title{
Rapid whole-genome sequencing identifies a novel GABRA1 variant associated with West syndrome
}

\author{
Lauge Farnaes, ${ }^{1}$ Shareef A. Nahas, ${ }^{1}$ Shimul Chowdhury, ${ }^{1}$ James Nelson, ${ }^{2}$ \\ Serge Batalov, ${ }^{1}$ David M. Dimmock, ${ }^{1}$ Stephen F. Kingsmore, ${ }^{1}$ and on behalf of the \\ RCIGM Investigators ${ }^{1}$
}

\footnotetext{
${ }^{1}$ Rady Children's Institute of Genomic Medicine (RCIGM), San Diego, California 92123, USA; ${ }^{2}$ Department of Neurosciences, University of California, San Diego, La Jolla, California 92093, USA
}

Abstract A 9-mo-old infant was admitted with infantile spasms that improved on administration of topiramate and steroids. He also had developmental delay, esotropia, and hypsarrhythmia on interictal electroencephalogram (EEG), and normal brain magnetic resonance imaging (MRI). West syndrome is the triad of infantile spasms, interictal hypsarrhythmia, and mental retardation. Rapid trio whole-genome sequencing (WGS) revealed a novel, likely pathogenic, de novo variant in the gene encoding $\gamma$-aminobutyric acid (GABA) type A receptor, a1 polypeptide (GABRA1 c.789G>A, p.Met263lle) in the proband. GABRA1 mutations have been associated with early infantile epileptic encephalopathy type 19 (EIEE19). We suggest that GABRA1 p.Met263lle is associated with a distinct West syndrome phenotype.

[Supplemental material is available for this article.]

\section{CASE PRESENTATION}

Corresponding author: skingsmore@rchsd.org

(c) 2017 Farnaes et al. This article is distributed under the terms of the Creative Commons Attribution-NonCommercial License, which permits reuse and redistribution, except for commercial purposes, provided that the original author and source are credited.

Ontology terms: developmental regression; generalized neonatal hypotonia; infantile spasms

Published by Cold Spring Harbor Laboratory Press

doi: 10.1101/mcs.a001776
The patient was a 9-mo-old male born at term via repeat Cesarean section without complications. He had been noted to have right-sided esotropia since 4 mo of age. The patient was referred to a metabolic clinic because of elevated plasma lactate on three occasions (4.3-6.0 $\mathrm{mmol} / \mathrm{l}$ [reference range $<2.2 \mathrm{mmol} / \mathrm{l}])$ at $5 \mathrm{mo}$ of age, but this had normalized $(1.3 \mathrm{mmol} / \mathrm{l})$ when seen in metabolic clinic the following month. Pyruvic acid and ammonia were also normal at the time of evaluation, but creatinine kinase was slightly elevated at $150 \mathrm{U} / \mathrm{l}$. He had neurodevelopmental delay evidenced by poor head control and inability to roll over independently at 6 mo of age. The clinician evaluating him at 6 mo of age was unable to fully extend his upper and lower extremities because of hypertonia. (See Table 1.) The patient had a normal brain magnetic resonance imaging (MRI). At 9 mo of age he was brought to the Rady Children's Hospital-San Diego emergency department because of concern over abnormal involuntary movements. He had been developing decreasing responsiveness for $10 \mathrm{~d}$ and developed an elevated temperature $\left(102^{\circ} \mathrm{F}\right)$ after which the abnormal movements increased in frequency. At the time of admission he had a mildly elevated plasma lactate $(3.1 \mathrm{mmol} / \mathrm{l})$. The patient's fever resolved within $24 \mathrm{~h}$ without an identified infectious etiology. A video electroencephalogram (EEG) at admission to the Pediatric Intensive Care Unit showed evidence of infantile spasms (Supplemental Data 1). These were treated with high-dose intravenous methylprednisolone, and stopped after $1 \mathrm{~d}$. A brain MRI with spectroscopy and spine MRI were normal. The patient's lactate normalized and he had a 


\begin{tabular}{|c|c|c|}
\hline $\begin{array}{l}\text { Early infantile epileptic } \\
\text { encephalopathy }-19\end{array}$ & $\begin{array}{c}\text { Proband } \\
\text { (II-1) }\end{array}$ & Comments \\
\hline $\begin{array}{l}\text { Onset of seizures between ages } 8 \text { and } \\
11 \text { months }\end{array}$ & Yes & \\
\hline Hemiclonic seizures & No & \\
\hline Tonic-clonic seizures & No & \\
\hline Focal dyscognitive seizures & No & \\
\hline Myoclonic seizures & No & \\
\hline Absence seizures & No & \\
\hline Atonic seizures & No & \\
\hline Status epilepticus & No & \\
\hline Febrile sensitivity to seizures & Yes & Not febrile seizures \\
\hline Intellectual disability & Yes & Developmental delay and regression \\
\hline $\begin{array}{l}\text { EEG with generalized spike-wave } \\
\text { discharges or focal discharges }\end{array}$ & Yes & \\
\hline Calcified ependymal nodule on MRI & No & \\
\hline \multicolumn{3}{|l|}{ Novel clinical features } \\
\hline Infantile spasms & Yes & $\begin{array}{l}\text { Not mentioned in OMIM, but reported in one } \\
\text { case (Kodera et al. 2016) }\end{array}$ \\
\hline Esotropia & Yes & \\
\hline Infantile muscular hypertonia & Yes & $\begin{array}{l}\text { Probably secondary to infantile spasms (Díaz } \\
\text { Negrillo et al. 2011; Raviglione et al. 2016) }\end{array}$ \\
\hline
\end{tabular}

The list of clinical features are based on the OMIM clinical synopsis related to the GABRA1 gene (\#615744; Epileptic encephalopathy, early infantile, 19). No features on the list were noted in either parent.

EEG, electroencephalogram; MRI, magnetic resonance imaging; OMIM, Online Mendelian Inheritance in Man.

complete metabolic workup during admission, which was unremarkable (Supplemental Data 2). The patient and his parents underwent rapid trio whole-genome sequencing (WGS) to determine the spasm etiology. He was discharged on oral steroids and topiramate. One week later he had a repeat video EEG that showed frequent, irregular, short sets of high-voltage, biposterior, $\Delta$ waves in the awake state, in the absence of seizures.

The patient has an unaffected 6-yr-old brother. His parents are both $34 \mathrm{yr}$ old. His maternal and paternal families were from India, with no known consanguinity. There were no other family members with childhood health issues.

\section{TECHNICAL ANALYSIS AND METHODS}

A chromosomal microarray (Quest Diagnostics) revealed a likely benign 61-kb interstitial deletion at Chr 2p13.3, which encompasses the genes encoding F-box protein 48 (FBX048), aprataxin (APTX), and PNKP-like factor (APLF).

Four days after consent for trio WGS, DNA was extracted and sequenced using an Illumina HiSeq X with paired 151-nt reads. Sequencing was completed $12 \mathrm{~d}$ after consent. Rapid alignment and nucleotide variant calling was performed using the DRAGEN (Edico Genome) hardware and software (Miller et al. 2015). The yield was 176.2, 180.8, and $161.5 \mathrm{~Gb}$ for the proband, mother, and father, respectively, resulting in 4,531,103, $4,888,177$, and 4,868,923 distinct variant calls, respectively (Table 2). 
Table 2. Sequencing data

\begin{tabular}{|c|c|c|c|c|c|}
\hline & Proband & Mother & Father & Units & Reference range \\
\hline Sex/trio order & $M$ verified & F verified & $M$ verified & & $\begin{array}{l}\text { Trio order } \\
\text { verified }\end{array}$ \\
\hline Yield: raw/bulk & 176.2 & 180.8 & 161.5 & $\mathrm{~Gb}$ & $>180$ \\
\hline Percent of mapped & $98.95 \%$ & $98.91 \%$ & $98.98 \%$ & pct & $98-100$ \\
\hline Percent of duplicates & $11.21 \%$ & $9.25 \%$ & $10.97 \%$ & pct & $<15 \%$ \\
\hline Yield & 154.9 & 162.4 & 142.3 & $\mathrm{~Gb}$ & $>130$ \\
\hline Insert size: mean $\pm \mathrm{SD}$ & $362 \pm 128$ & $373 \pm 122$ & $360 \pm 112$ & bp & $300-480$ \\
\hline Average and median coverage across genome & 46.0 & 48.0 & 43.0 & $x$ & $>40$ \\
\hline Average coverage over OMIM genes & 47.0 & 48.0 & 44.0 & $x$ & $>40$ \\
\hline $\begin{array}{l}\text { Number of OMIM genes with coverage at }<10 x \\
\text { (and list) }\end{array}$ & 268 & 241 & $>292$ & ENST & $<2 \%(282)$ \\
\hline $\begin{array}{l}\text { Number of OMIM genes with } 100 \% \text { coverage at } \\
\geq 10 \times\end{array}$ & $98.1 \%$ & $98.3 \%$ & $97.9 \%$ & pct & $>98 \%$ \\
\hline $\begin{array}{l}\text { Number of OMIM genes with } 100 \% \text { coverage at } \\
\geq 20 \times\end{array}$ & $93.4 \%$ & $97.0 \%$ & $92.9 \%$ & pct & $>94 \%$ \\
\hline $\begin{array}{l}\text { Number of OMIM genes with } 100 \% \text { coverage at } \\
\geq 30 \times\end{array}$ & $84.1 \%$ & $88.9 \%$ & $75.9 \%$ & pct & $>80 \%$ \\
\hline Number of genes with $100 \%$ coverage at $\geq 40 \times$ & $31.5 \%$ & $37.1 \%$ & $15.6 \%$ & & \\
\hline \multicolumn{6}{|l|}{ Variation (VCF) metrics } \\
\hline Number of calls (Total) & $4,853,103$ & $4,888,177$ & $4,868,923$ & & $2.5-6.0 \times 10^{6}$ \\
\hline Number of PASS calls & $4,760,785$ & $4,821,561$ & $4,772,816$ & & $2.5-6.0 \times 10^{6}$ \\
\hline Number of calls total coding & 26,917 & 27,093 & 27,282 & & $25,000-30,000$ \\
\hline Total number of SNVs & $3,982,176[82.05 \%]$ & $4,010,837[82.05 \%]$ & $3,998,391[82.12 \%]$ & & \\
\hline Total number of Indels & 870,927 [17.95\%] & $877,340[17.95 \%]$ & $870,532[17.88 \%]$ & & \\
\hline Hom/Het ratio (in coding regions) & $0.58(0.61)$ & $0.57(0.59)$ & $0.58(0.58)$ & Ratio & $0.5-0.61$ \\
\hline $\mathrm{Ti} / \mathrm{Tv}$ ratio (in coding regions) & $2.04(2.94)$ & $2.04(2.92)$ & $2.04(2.94)$ & Ratio & $2-2.2(2.8-3)$ \\
\hline Number of het calls (Number of hom calls) & $\begin{array}{l}3,107,938 \\
(18,498,22)\end{array}$ & $\begin{array}{l}3,205,140 \\
(1,789,679)\end{array}$ & $\begin{array}{c}3,128,433 \\
(1,842,666)\end{array}$ & Units & \\
\hline In silico sample swap check & PASS & PASS & PASS & & Mendelian test \\
\hline Automated upload of VCF to Omicia & PASS & PASS & PASS & & \\
\hline Inform sign-out of analysis-ready state & PASS & PASS & PASS & & \\
\hline $\begin{array}{l}\text { Detect sample analysis completion state on } \\
\text { Omicia }\end{array}$ & PASS & PASS & PASS & & \\
\hline
\end{tabular}

SD, standard deviation; OMIM, Online Mendelian Inheritance in Man; VCF, variant call format; SNVs, single-nucleotide variants; Hom/Het, homogeneous/ heterogeneous; Ti/TV, transition/transversion.

Variants were annotated and analyzed in Opal Clinical (Omicia) (Coonrod et al. 2013). Initially, variants were filtered to retain those with allele frequencies of $<1 \%$ in the Exome Variant Server, 1000 Genomes samples, and Exome Aggregation Consortium database (http://evs.gs.washington.edu/EVS/. 2016; Karczewski et al. 2016). A differential diagnostic gene list was built in Phenolyzer (Yang et al. 2015) using Human Phenotype Ontology (HPO) (Köhler et al. 2016) and Systematized Nomenclature of Medicine-Clinical Terms (SNOMED-CT(SNOMED)). The following codes were used HP:0012469 (infantile spasms, SCTID: 28055006), HP:0001250 (seizures, SCTID: 91175000), HP:0002376 (developmental regression, SCTID: 248290002), HP:0000565 (esotropia, SCTID: 16596007), and HP:0008947 (infantile muscular hypotonia, SCTID: 205294008) (hypotonia was used in the initial 


\begin{tabular}{|c|c|c|c|c|c|c|}
\hline Gene & Genomic location & HGVS cDNA & HGVS protein & Zygosity & $\begin{array}{l}\text { Parent of } \\
\text { origin }\end{array}$ & $\begin{array}{l}\text { Variant } \\
\text { interpretation }\end{array}$ \\
\hline GABRA1 & $\begin{array}{l}\text { NC_000005.10 (on Assembly GRCh38): } \\
\text { g.161890983G>A }\end{array}$ & $\begin{array}{l}\text { NM_000806.5: } \\
\text { c.789G }>A\end{array}$ & $\begin{array}{l}\text { NP_000797.2 } \\
\text { p.Met263lle }\end{array}$ & Heterozygous & De novo & Likely pathogenic \\
\hline
\end{tabular}

HGVS, Human Genome Variation Society.

evaluation rather than hypertonia due to the prolonged history of poor head control), yielding 1465 genes (Supplemental Data 3). Research on the optimal number of phenotypic findings to use for creation of a gene list is ongoing at RCIGM; until research is complete we are including all relevant phenotypic findings. Variants were further filtered to retain those mapping to these 1465 genes, yielding 76 proband calls (six homozygous variants, 63 heterozygous inherited variants, and seven heterozygous de novo variants) (see Supplemental Data 4). Manual curation revealed one of these as pathogenic (one strong, two moderate, and two supporting criteria) (Supplemental Data 5,6) by American College of Medical genetics and Genomics (ACMG) guidelines (Richards et al. 2015). However, as per laboratory protocol a designation of "likely" pathogenic was reported, as this nucleotide variant had not previously been reported in any other affected individuals. (See Table 3.)

\section{VARIANT INTERPRETATION}

This patient was heterozygous for a novel likely pathogenic c.789G >A (p.Met263lle) variant in the gene encoding the $\gamma$-aminobutyric acid (GABA) type A receptor, a1 polypeptide gene (GABRA1). GABA is the major inhibitory neurotransmitter in the mammalian brain. It acts at GABA-A receptors, which are ligand-gated chloride channels (Carvill et al. 2014). This gene is associated with generalized epilepsy (Lachance-Touchette et al. 2011), juvenile myoclonic epilepsy (Cossette et al. 2002), absence epilepsy (Maljevic et al. 2006), and early infantile epileptic encephalopathy type 19 (EIEE19), which is autosomal dominant, with the onset of recurrent seizures in childhood or adolescence (Epi4K Consortium et al. 2013). Affected individuals can have a wide variety of seizures, including febrile sensitivity to seizures, as in the present case. Esotropia has not previously been associated with EIEE19. GABRA1 was 538th on the 1465 Phenolyzer gene list (Score 0.002), and had a probability of match to GABRA1 of 0.016 when the same HPO terms were analyzed in Phenomizer (Köhler et al. 2009). GABRA1 had a haploinsufficiency score of 0.46 and a gene intolerance score of 0.76 .

A different variant at the same codon (c.788T>C, p.Met263Thr) has been previously reported to be likely pathogenic (ClinVar Accession number RCV000187499.2). Furthermore, a missense variant at a different nucleotide in the same codon $(c .789 \mathrm{G}>\mathrm{C}$ ), which resulted in the same amino acid change (p.Met263lle) as the current patient, was reported as pathogenic in a patient with West syndrome (Kodera et al. 2016). The latter patient did not receive a molecular diagnosis until age 9. However, that patient had also shown hypsarrhythmia on EEG at the age of 6 mo. That patient had normal development until the age of 6 mo and then developed developmental delay. That patient also had a normal brain MRI.

The provisional diagnosis was made within $6 \mathrm{~h}$ of completion of the sequencing run (see Supplemental Figure 7 for current institute workflow). The research protocol under which the trio received rapid WGS was approved by the Food and Drug Administration, and the local Institutional Review Board requires confirmation by a clinically accepted standard before 
COLD SPRING HARBOR Molecular Case Studies
Novel GABRA1 variant associated with West syndrome reporting, except in cases of actionable diagnoses in which major morbidity or likelihood of mortality is likely during confirmatory testing. EIEE19 is an actionable diagnosis, but there was very low likelihood of major morbidity or mortality during confirmatory testing. Therefore, the clinical team was notified of the result after Sanger confirmation (day 28).

The diagnosis explained the etiology of the infant's seizures, and confirmed that the antiepileptic regimen was appropriate. The infant did well on steroids and topiramate and was gradually weaned off steroids. Several specific GABA-A receptor agonists and modulators have been developed as anticonvulsants and may represent potentially more targeted therapies for patients with refractory EIEE19 than topiramate (García-Flores and Farías 1997).

\section{SUMMARY}

GABRA1 p.Met263lle resulting from c.789G >A (reported herein) or c.789G >C (reported previously) appears to be associated with a distinct EIEE19 phenotype that fits the definition of West syndrome (triad of infantile spasms, interictal hypsarrhythmia, and mental retardation): both patients had infantile spasms (clinical diagnosis in the present patient, previous patient with hypsarrhythmia on EEG) between 6 and 9 mo of age (Kodera et al. 2016). Both patients had normal MRIs and significant developmental delay. The rapidity of provisional diagnosis by rapid WGS has the potential to enable precision medicine for genetically heterogeneous infantile seizure disorders. A rapid diagnosis may be able to avoid further or unnecessary diagnostic steps. In this case the patient did not have a muscle biopsy to diagnose a mitochondrial disorder and the diagnostic odyssey was brief. If the patient had been referred to us before his extensive metabolic workup, extensive blood tests and laboratory work could have been avoided. The prior reported case with this same protein change had hypsarrhythmia detected at 6 mo of age, but the molecular etiology was not determined until he was $9 \mathrm{yr}$ old. Although the medical therapy was not changed because of sequencing in this case, further workup for treatable causes was avoided. In addition, a firm diagnosis reassured the clinical team and family that the child was on the right therapy.

\section{ADDITIONAL INFORMATION}

\section{Data Deposition and Access}

Sequencing data has been submitted to DNAnexus (https://platform.dnanexus.com/ projects/F670ff00gp1K0Z1×4Y×84VXj/data/WestSyndrome). Variant was submitted to ClinVar and can be found under accession number SCV000494287.1 (https://www.ncbi. nlm.nih.gov/clinvar).

\section{Ethics Statement}

Informed consent was obtained for all individuals in this study, both to undertake rapid whole-genome sequencing and to publish these findings. The study was approved by Institutional Review Board of the University of California at San Diego under protocol \#160468 and has received nonsignificant risk status in a pre-Investigational Device Exemption submission to the Food and Drug Administration.

\section{Author Contributions}

L.F. contributed to manuscript preparation and phenotyping; S.A.N. contributed to variant interpretation and manuscript preparation; S.C. contributed to variant interpretation and manuscript preparation; J.N. contributed to clinical implementation and manuscript 
COLD SPRING HARBOR Molecular Case Studies
Novel GABRA1 variant associated with West syndrome
Competing Interest Statement

The authors have declared no competing interest.

\section{Referees}

Ralph J. DeBerardinis

Anonymous

Received January 13, 2017; accepted in revised form March 14,2017 preparation; D.M.D. contributed to supervision and manuscript preparation; S.B. contributed to Bioinformatics; S.F.K. contributed to supervision and manuscript preparation. RCIGM Investigators contributed to process development, infrastructure deployment, and maintenance. All authors contributed to the reviewing of the final version.

Contributors at Rady Children's Institute for Genomic Medicine Investigators were Julie Cakici, Michelle Clark, Yan Ding, Jennifer Friedman, Joseph Gleeson, Jeffrey Gold, Amber Hildreth, Farhad Imam, Sara Martin, Julie Ryu, Nathaly Sweeney, and Narayanan Veeraraghavan.

\section{Funding}

This study was supported by Rady Children's Hospital and National Institute of Child Health and Human Development and National Human Genome Research Institute (grant no. U19HD077693).

\section{REFERENCES}

Carvill GL, Weckhuysen S, McMahon JM, Hartmann C, Møller RS, Hjalgrim H, Cook J, Geraghty E, O’Roak BJ Petrou S, et al. 2014. GABRA1 and STXBP1: novel genetic causes of Dravet syndrome. Neurology 82: $1245-1253$.

Coonrod EM, Margraf RL, Russell A, Voelkerding KV, Reese MG. 2013. Clinical analysis of genome next-generation sequencing data using the Omicia platform. Expert Rev Mol Diagn 13: 529-540.

Cossette P, Liu L, Brisebois K, Dong H, Lortie A, Vanasse M, Saint-Hilaire JM, Carmant L, Verner A, Lu WY, et al. 2002. Mutation of GABRA1 in an autosomal dominant form of juvenile myoclonic epilepsy. Nat Genet 31: 184-189.

Díaz Negrillo A, Martín Del Valle F, González Salaices M, Prieto Jurczynska C, Carneado Ruiz J. 2011. Levetiracetam efficacy in patients with Lennox-Gastaut syndrome. Presentation of a case. Neurologia 26: 285-290.

Epi4K Consortium; Epilepsy Phenome/Genome Project, Allen AS, Berkovic SF, Cossette P, Delanty N, Dlugos D, Eichler EE, Epstein MP, Glauser T, Goldstein DB, et al. 2013. De novo mutations in epileptic encephalopathies. Nature 501: 217-221.

García-Flores E, Farías R. 1997. $\gamma$-Amino- $\beta$-hydroxybutyric acid as add-on therapy in adult patients with severe focal epilepsy. Stereotact Funct Neurosurg 69: 243-246.

http://evs.gs.washington.edu/EVS/. 2016. NHLBI, Exome Variant Server. GO Exome Sequencing Project (ESP). Seattle, WA.

Karczewski KJ, Weisburd B, Thomas B, Solomonson M, Ruderfer DM, Kavanagh D, Hamamsy T, Lek M, Samocha KE, Cummings BB, et al. 2016. The ExAC browser: displaying reference data information from over 60000 exomes. Nucleic Acids Res 45: D840-D845.

Kodera H, Ohba C, Kato M, Maeda T, Araki K, Tajima D, Matsuo M, Hino-Fukuyo N, Kohashi K, Ishiyama A, et al. 2016. De novo GABRA1 mutations in Ohtahara and West syndromes. Epilepsia 57: 566-573.

Köhler S, Schulz MH, Krawitz P, Bauer S, Dölken S, Ott CE, Mundlos C, Horn D, Mundlos S, Robinson PN. 2009. Clinical diagnostics in human genetics with semantic similarity searches in ontologies. Am J Hum Genet 85: 457-464.

Köhler S, Vasilevsky NA, Engelstad M, Foster E, McMurry J, Aymé S, Baynam G, Bello SM, Boerkoel CF، Boycott KM, et al. 2016. The Human Phenotype Ontology in 2017. Nucleic Acids Res 45: D865-D876.

Lachance-Touchette P, Brown P, Meloche C, Kinirons P, Lapointe L, Lacasse H, Lortie A, Carmant L, Bedford F, Bowie $D$, et al. 2011. Novel $\alpha 1$ and $\gamma 2 \mathrm{GABA}_{A}$ receptor subunit mutations in families with idiopathic generalized epilepsy. Eur J Neurosci 34: 237-249.

Maljevic S, Krampfl K, Cobilanschi J, Tilgen N, Beyer S, Weber YG, Schlesinger F, Ursu D, Melzer W, Cossette $P$, et al. 2006. A mutation in the $\mathrm{GABA}_{\mathrm{A}}$ receptor $\alpha_{1}$-subunit is associated with absence epilepsy. Ann Neurol 59: 983-987.

Miller NA, Farrow EG, Gibson M, Willig LK, Twist G, Yoo B, Marrs T, Corder S, Krivohlavek L, Walter A, et al. 2015. A 26-hour system of highly sensitive whole genome sequencing for emergency management of genetic diseases. Genome Med 7: 100. 
Raviglione F, Conte G, Ghezzi D, Parazzini C, Righini A, Vergaro R, Legati A, Spaccini L, Gasperini S, Garavaglia B, et al. 2016. Clinical findings in a patient with FARS2 mutations and early-infantile-encephalopathy with epilepsy. Am J Med Genet A 170: 3004-3007.

Richards S, Aziz N, Bale S, Bick D, Das S, Gastier-Foster J, Grody WW, Hegde M, Lyon E, Spector E, et al. 2015. Standards and guidelines for the interpretation of sequence variants: a joint consensus recommendation of the American College of Medical Genetics and Genomics and the Association for Molecular Pathology. Genet Med 17: 405-424.

SNOMED. SNOMED-CT Systematized Nomeclature of Medicine-Clinical Terms. http://www.ihtsdo.org/ snomed-ct Accessed 12/29/2016.

Yang H, Robinson PN, Wang K. 2015. Phenolyzer: phenotype-based prioritization of candidate genes for human diseases. Nat Methods 12: 841-843. 


\section{COLD SPRING HARBOR Molecular Case Studies}

\section{Rapid whole-genome sequencing identifies a novel GABRA1 variant associated with West syndrome}

Lauge Farnaes, Shareef A. Nahas, Shimul Chowdhury, et al.

Cold Spring Harb Mol Case Stud 2017, 3: a001776 originally published online May 11, 2017 Access the most recent version at doi: $10.1101 / \mathrm{mcs} .0001776$
Supplementary http://molecularcasestudies.cshlp.org/content/suppl/2017/05/11/mcs.a001776.D Material C1
License This article is distributed under the terms of the Creative Commons Attribution-NonCommercial License, which permits reuse and redistribution, except for commercial purposes, provided that the original author and source are credited.
Email Alerting Receive free email alerts when new articles cite this article - sign up in the box at the Service top right corner of the article or click here.

